\title{
Telomerase RNA Levels Limit the Telomere Length Equilibrium
}

\author{
C.W. GREIDER \\ Department of Molecular Biology and Genetics, Johns Hopkins \\ University School of Medicine, Baltimore, Maryland 21205
}

\begin{abstract}
Small functional RNAs play essential roles in many biological processes. Regulating the level of these small RNAs can be as important as maintaining their function in cells. The telomerase RNA is maintained in cells at a steady-state level where small changes in concentration can have a profound impact on function. Cells that have half the level of the telomerase RNA cannot maintain telomeres through many cell divisions. People who are heterozygous for telomerase RNA mutations have the diseases dyskeratosis congenita and aplastic anemia, caused by short telomeres that result in loss of tissue renewal capacity. Mice heterozygous for telomerase RNA show haploinsufficiency in telomere length maintenance and also show loss of tissue renewal capacity. It is remarkable that small changes in the level of this functional RNA can have such profound effects in cells. This tight regulation highlights the importance of controlling the action of telomerase in cells.
\end{abstract}

Work over the past 20 years has shown that functional RNAs play important roles in cells. While much of the focus is on the precise mechanisms of RNA function, less attention has been focused on the importance of the level of specific functional RNAs. The RNA component of telomerase is essential for telomere maintenance. Recent experiments on the telomerase RNA have shown that changes in the level of this functional RNA have major consequences for telomere length regulation. Reduced RNA levels compromise cell viability and cause human disease. Because telomerase RNA is maintained at an equilibrium concentration well below saturation, small changes in RNA concentration can affect enzyme action. The exquisite regulation of this small RNA highlights the role of maintaining the equilibrium concentration of small functional RNAs; tight regulatory balance is likely used to regulate RNAs that play roles in other cellular processes.

\section{TELOMERASE IS REQUIRED FOR TELOMERE LENGTH MAINTENANCE}

Telomeres are the protein-DNA structures that protect chromosome ends from nucleases and recombination and distinguish these natural chromosome ends from broken DNA. When telomere function is lost, the chromosome end resembles a double-stranded DNA break and can result in chromosome end-to-end fusion and other rearrangements. Telomerase is a remarkable enzyme that maintains telomere length and thus helps assure telomere function. The normal mechanisms that replicate chromosome ends lead to a loss of telomere sequence each time the cell divides (Watson 1972; Olovnikov 1973). Telomerase overcomes this end replication problem, by adding telomere sequences back onto chromosome ends (Greider and Blackburn 1985). Telomerase enzymes from all eukaryotes contain two essential core enzyme components, a catalytic protein component, TERT, and the telomerase RNA component, or TR (Lingner et al. 1997). The telomerase RNA component contains a short, singlestranded sequence that serves as the template for the telomeric sequences that are added onto chromosome ends by the enzyme (Greider and Blackburn 1989). In addition to the template region, the telomerase RNA structure contains regions that are essential in the catalytic function of the enzyme (Chen and Greider 2004).

\section{TELOMERE LENGTH EQUILIBRIUM IS MAINTAINED BY REGULATING ACCESS OF TELOMERASE TO TELOMERES}

Telomerase maintains telomere length by adding telomere repeats onto some, but not all, chromosome ends at each cell division. The shortest telomeres in the cell are preferentially elongated by telomerase. Thus, the length of each individual telomere is maintained as an equilibrium between shortening due to replication and lengthening by telomerase. This equilibrium is maintained within a defined set point through a series of feedback mechanisms that regulate repeat addition (Greider 1996; Smogorzewska and de Lange 2004). The specific set point for the equilibrium length is species specific; in yeast the average is around $300 \mathrm{bp}$, whereas in humans it is around 10,000 bp. Within a species, different strains may have different telomere length set points, and this set point is genetically defined (Craven and Petes 1999; Hemann and Greider 2000).

Telomere length equilibrium is regulated by at least two different mechanisms: telomere-binding proteins and modification of those proteins at the telomere. In both yeast and mammals there is a specific set of telomere proteins that bind telomeric DNA to protect the end and distinguish the telomere from a double strand break. Access of telomerase to the telomere is negatively regulated by these telomerebinding proteins (Shore 1997a; Smogorzewska and de Lange 2004; de Lange 2005). The bound telomere protein complex somehow blocks the ability of telomerase to elongate the telomere. This inhibition of telomerase elongation directly at the telomere establishes a feedback mechanism that regulates how long telomeres can get. The longer the telomere, the more telomere-binding proteins are present, 
the stronger the block to telomerase elongation of that specific telomere (Shore 1997b; Smogorzewska and de Lange 2004). This simple feedback system is also regulated by protein modification. Phosphorylation of specific substrates by the ATM and ATR protein kinases is required to allow telomerase access to elongate the telomere (Naito et al. 1998; Ritchie et al. 1999). In addition, the $\mathrm{Cdk} 1$ kinase also regulates telomere elongation (Frank et al. 2006; Vodenicharov and Wellinger 2006). The specific targets of phosphorylation and the mechanisms by which these modifications establish and maintain the length equilibrium are not yet understood in detail. This is an active area of ongoing research.

\section{TELOMERASE IS REQUIRED IN CELLS THAT MUST DIVIDE MANY TIMES}

Telomerase is essential to maintain telomere length through many cell divisions. Experimentally, deletion of either the RNA or protein component of telomerase leads to progressive telomere shortening as cells undergo multiple rounds of DNA replication (Lundblad and Szostak 1989; Singer and Gottschling 1994; Blasco et al. 1997; Lingner et al. 1997). The absence of telomerase initially has no effect on cells when telomeres are long. As the cells divide and telomeres shorten, the short telomeres trigger a DNA damage response and cell cycle arrest or apoptosis (Hemann et al. 2001a; Enomoto et al. 2002; d'Adda di Fagagna et al. 2003; IJpma and Greider 2003; Hao et al. 2004). Short telomeres are thought to trigger this DNA damage response because when telomeres become too short they no longer provide the protective function, and the chromosome end now resembles a DNA break (Hemann et al. 2000, 2001a).

Telomere maintenance is essential for cells that must divide many times. Single-celled organisms, like yeast, require telomerase for long-term growth (Lundblad and Szostak 1989). In mammals, telomerase is essential for tissues that require constant renewal. In these tissues, telomeres must be maintained specifically in stem cells that are responsible for maintaining tissue integrity. In mice, deletion of the telomerase RNA gene, mTR, causes progressive telomere shortening with increased generations of interbreeding. When telomeres are short, cell death occurs in tissues that undergo constant cell division (Lee et al. 1998; Hao et al. 2005). Short telomeres cause cell death in the testes, leading to loss of fertility (Hemann et al. 2001b). These mice also show decreased cellularity of the bone marrow and spleen and a loss of the villi in the gastrointestinal tract (Hao et al. 2005). The fact that all of the affected tissues in these mice with short telomeres are those that undergo constant turnover suggests that telomere maintenance is required for the long-term integrity of stem cells.

Telomerase is also required in cancer cells to allow for the large number of cell divisions these cells undergo during tumor initiation and growth. Telomeres are typically shorter in cancer cells than in normal cells, likely due to the large number of cell divisions that these cells have undergone. Genetic crosses between the $\mathrm{mTR}^{-1-}$ mouse and several tumor-prone mouse models reveal that telo- mere shortening can limit tumor growth (Greenberg et al. 1999; Rudolph et al. 2001; Qi et al. 2003; Wong et al. 2003). The short telomeres signal through the DNA damage response pathway and limit tumor cell proliferation and thus limit tumor growth. These results support the proposals which have been made (Greider 1990; Harley et al. 1990; Shay and Wright 2002) that inhibiting telomerase may be an effective approach to cancer treatment.

\section{THE SHORTEST TELOMERES LIMIT CELL DIVISION}

The powerful ability of short telomeres to limit cell division and tissue renewal raises the question of the mechanism by which short telomeres exert this effect. Experiments with the telomerase null mice demonstrated that, at the molecular level, it is the shortest telomere that limits cell division. As the telomerase null mouse is bred for multiple generations, in the first few generations, when telomeres are long, there are no cellular or organismal phenotypes. However, in the later $\mathrm{mTR}^{-/-}$generations, when the telomeres are sufficiently short, loss of tissue regenerative capacity is seen. This implies that it is not the absence of telomerase itself, but rather the short telomeres, that elicits the cell growth inhibition. This effect of short telomeres is exerted by the shortest telomeres in the cell, not by an overall shortening of the telomere length distribution. When mTR heterozygous mice with long telomeres were crossed to telomerase null mice with short telomeres, the null progeny had critically short telomeres and showed cell death. In the $\mathrm{mTR}^{+/-}$littermates, the critically short telomeres were elongated by telomerase, but the overall length distribution was identical to that in the $\mathrm{mTR}^{-/-}$ mice. This indicates that all of the phenotypes associated with telomere shortening are due to the shortest telomeres in the distribution, and telomerase is targeted to preferentially elongate the shortest telomeres (Hemann et al. 2001a). Thus, only a few short telomeres needed to be elongated to allow cell viability. This observation highlights the extent of fine-tuning of telomere length regulation in cells; very subtle changes in telomere length maintenance can determine whether a cell lives or dies.

\section{HALF THE LEVEL OF TELOMERASE RNA IS NOT SUFFICIENT FOR TELOMERE MAINTENANCE}

The fine-tuning of telomere length is regulated by the level of active telomerase enzyme. The importance of the level of telomerase in cells is evident from the human genetic disease dyskeratosis congenita. Mutations in the telomerase RNA gene cause autosomal dominant dyskeratosis congenita (Vulliamy et al. 2001). In this genetic disease, patients have short telomeres and most often die of bone marrow failure. This bone marrow failure likely represents a defect in the self-renewal capacity of the hematopoietic progenitor cells. The telomerase null mouse shows similar telomere shortening and loss of bone marrow regenerative capacity. Strikingly, patients with autosomal dominant dyskeratosis congenita have only one mutant allele of the telomerase RNA gene. 
Autosomal dominant inheritance can be caused by a dominant interfering mutation that inactivates the product of the wild-type allele, or it can be due to haploinsufficiency, where half the level of the normal enzyme is not sufficient for an essential function.

To test whether half the level of telomerase RNA limits telomere elongation, we bred heterozygous $\mathrm{mTR}^{+/}$mice. Quantitative RT-PCR showed that $\mathrm{mTR}^{+/-}$mice have half of the steady-state level of telomerase RNA (Hathcock et al. 2002). When $\mathrm{mTR}^{+/}$mice were bred for multiple generations and maintained as heterozygotes (Fig. 1), they showed progressive telomere shortening (Hao et al. 2005). This telomere shortening in the presence of half the level of telomerase RNA implies haploinsufficiency for telomerase in telomere length maintenance. The late generation heterozygous mice that had short telomeres showed cell death in the testes and decreased tissue renewal capacity, similar to the $\mathrm{mTR}^{-/}$mice with short telomeres. This loss of tissue renewal provides direct genetic evidence for haploinsufficiency in the human autosomal dominant disease dyskeratosis congenita.

The telomere shortening with increased generations of breeding in $\mathrm{mTR}^{+/-}$heterozygous mice implies that telomerase is maintained in cells at a very low level that is just barely enough to maintain the length equilibrium; any decrease in the level perturbs the telomere length equilibrium. The effects of limiting telomerase can last for many generations. The wild-type offspring from crosses of late-generation heterozygous mice (termed $\mathrm{Wt}^{*}$ mice; Fig. 1) still had short telomeres (Hao et al.
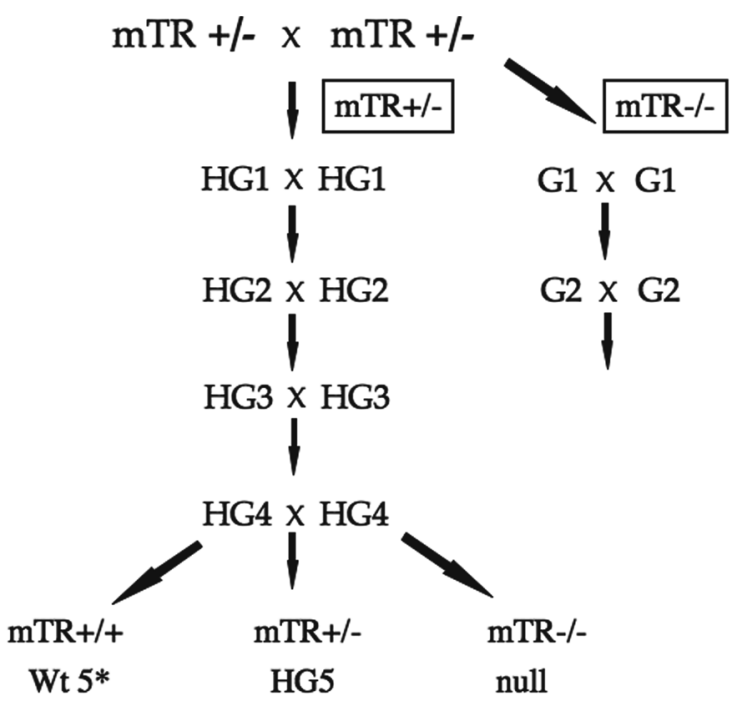

Figure 1. Breeding of telomerase heterozygous mice (see Hao et al. 2005). CAST/EiJ mice that were heterozygous for mouse telomerase RNA were bred to establish first-generation $\mathrm{mTR}^{-/}$ $\mathrm{G}_{1}$ mice. The $\mathrm{mTR}^{-/-} \mathrm{G}_{1}$ mice were bred to create second-generation $\mathrm{mTR}^{--} \mathrm{G}_{2}$ mice (right side). The first-generation heterozygotes HG1 were then bred together to create second-generation heterozygotes HG2, which in turn were interbred for additional generations (middle line). Telomere shortening occurred with each progressive generation of heterozygote. When the late-generation heterozygotes, HG4, were bred together, they established telomerase null $\mathrm{mTR}^{-/}$mice: the $\mathrm{HG} 5$ generation and $\mathrm{Wt} 5 *$ mice. These $\mathrm{Wt}^{*}$ mice had short telomeres compared to the parental wild-type mice that established this line.
2005). Thus, the amount of telomere elongation that occurs in germ-line cells in one generation even with wild-type levels of telomerase RNA is not sufficient to reestablish the wild-type telomere length distribution. Because short telomeres cause loss of cell viability, these wild-type mice with short telomeres showed similar loss of cell viability in testes as seen in $\mathrm{mTR}^{+/-}$heterozygotes and $\mathrm{mTR}^{-/}$mice with short telomeres (Hao et al. 2005). Preliminary experiments suggest that, after multiple generations of breeding these $\mathrm{Wt}^{*}$ mice, the telomere length is reestablished at the genetically determined wild-type telomere length set point. Thus, the limiting telomerase RNA has an effect for many generations.

As with other aspects of fundamental telomere function that are conserved, the sensitivity to telomerase RNA levels is also seen in yeast. Diploid yeast heterozygous for the telomerase RNA gene TLC1 have half of the steady-state level of telomerase RNA. Telomere shortening also occurs in these heterozygous yeast cells as they are grown continuously as heterozygotes (Mozdy and Cech 2006). This implies that the exquisite sensitivity to telomerase RNA levels is a conserved feature of telomere length regulation.

As described above, there are multiple independent mechanisms that regulate telomere length. How these different mechanisms interact to regulate the equilibrium set point is not yet clear. The fact that telomerase specifically targets the shortest telomeres and that the shortest telomeres limit cell proliferation might suggest that when telomerase is limiting, the shortest telomeres will be repaired first. However, this mechanism appears to be insufficient to restore all telomere function when telomerase is limiting. Both patients with autosomal dominant dyskeratosis congenita and the $\mathrm{mTR}^{+/-}$heterozygous mice show loss of bone marrow function with half the level of telomerase, thus, short telomeres must still be causing the phenotype despite some telomere elongation. This implies that even when telomerase is targeted to the shortest telomere, a reduction in the telomerase RNA level can still overwhelm the system so that short dysfunctional telomeres are still present.

\section{WHY IS TELOMERE ELONGATION SO TIGHTLY REGULATED?}

The fact that telomere length is maintained as an equilibrium distribution might suggest that there would be a lot of leeway in telomere length regulation. However, in fact, the opposite seems to be true. The cell expends a lot of energy regulating both access of telomerase to the telomere and the level of telomerase in a cell. Why would an apparently fairly loose length regulation system in fact be so exquisitely sensitive to small perturbations?

One obvious reason an organism might regulate telomerase would be as a tumor suppressor mechanism (Greider 1990; de Lange 1995). If telomere shortening does play the role of a tumor suppressor, as has been proposed, then a tight regulation of both telomere length and telomerase may be protective against cancer. This mechanism may explain a selection for tight telomerase regulation for mammals. However, tight regulation of telomerase also 
occurs in yeast and likely other single-celled organisms that do not get cancer. What purpose does the tight regulation of telomerase play at the cellular level? The answer may lie in the processing of double-stranded DNA breaks. Telomerase is known to add telomeric sequences onto broken DNA ends, creating new telomeres (Haber and Thorburn 1984; Greider 1991)w; although this process is inefficient, it results in functional chromosomes. For example, there are a number of truncations of human chromosome 16 that result in $\alpha$-thalassemia due to loss of the $\alpha$-globin gene (Wilkie et al. 1990; Lamb et al. 1993; Viprakasit et al. 2003). There are no known essential genes distal to $\alpha$-globin on chromosome 16 , thus if a DNA break occurs in $\alpha$-globin and telomere addition occurs, a new stable chromosome results. If telomerase were not so tightly regulated perhaps it would compete more effectively with the DNA repair machinery, and new telomeres would be added to chromosome breaks generating chromosome truncations before repair could occur. This would most often lead to loss of genes distal to the break and would be detrimental to the cell. Thus, to allow repair machinery to repair chromosome breaks, telomerase must not be allowed to access the break. The normal mechanisms that regulate telomere length through telomere-binding proteins would not offer regulation at a DNA break. Therefore, limiting the amount of telomerase in a cell may be the best way to assure it does not act where it should not.

\section{SUMMARY}

Telomerase is an essential enzyme that maintains telomere length. Despite the fact that telomere length is not precise, but rather regulated about a broad equilibrium, there is very tight regulation of both telomerase action and telomerase levels in the cell. One of the consequences of the very stringent regulation of telomerase is that having half the level of this enzyme is not sufficient to maintain telomeres, and this leads to human disease. It will be interesting to examine the processes that strictly regulate the level of telomerase in cells and the potential consequences to cells if that regulation is disturbed. These studies will give insights and possibly propose new avenues for treatment of patients with dyskeratosis congenita and other diseases caused by short telomeres.

\section{ACKNOWLEDGMENTS}

The work from the Greider lab described here was supported by National Institutes of Health grants RO1AG39383 and RO1AG027406. I thank the Greider lab members and Drs. Rachel Green, David Feldser, and Mary Armanios for critical reading of the manuscript.

\section{REFERENCES}

Blasco M.A., Lee H.-W., Hande M.P., Samper E., Lansdorp P.M., DePinho R.A., and Greider C.W. 1997. Telomere shortening and tumor formation by mouse cells lacking telomerase RNA. Cell 91: 25.

Chen J.L. and Greider C.W. 2004. Telomerase RNA structure and function: Implications for dyskeratosis congenita. Trends Biochem. Sci. 29: 183.
Craven R.J. and Petes T.D. 1999. Dependence of the regulation of telomere length on the type of subtelomeric repeat in the yeast Saccharomyces cerevisiae. Genetics 152: 1531.

d'Adda di Fagagna F., Reaper P.M., Clay-Farrace L., Fiegler H., Carr P., Von Zglinicki T., Saretzki G., Carter N.P., and Jackson S.P. 2003. A DNA damage checkpoint response in telomere-initiated senescence. Nature 426: 194.

de Lange T. 1995. Telomere dynamics and genome instability in human cancer. In Telomeres (ed. E.H. Blackburn and C.W. Greider), p. 265. Cold Spring Harbor Laboratory Press, Cold Spring Harbor, New York.

. 2005. Shelterin: The protein complex that shapes and safeguards human telomeres. Genes Dev. 19: 2100.

Enomoto S., Glowczewski L., and Berman J. 2002. MEC3, MEC1, and DDC2 are essential components of a telomere checkpoint pathway required for cell cycle arrest during senescence in Saccharomyces cerevisiae. Mol. Biol. Cell 13: 2626.

Frank C.J., Hyde M., and Greider C.W. 2006. Regulation of telomere elongation by the cyclin-dependent kinase CDK1. Mol. Cell 24: 423.

Greenberg R.A., Chin L., Femino A., Lee K.H., Gottlieb G.J., Singer R.H., Greider C.W., and DePinho R.A. 1999. Short dysfunctional telomeres impair tumorigenesis in the INK4a(delta2/3) cancer-prone mouse. Cell 97: 515.

Greider C.W. 1990. Telomeres, telomerase and senescence. Bioessays 12: 363.

- 1991. Chromosome first aid. Cell 67: 645.

1996. Telomere length regulation. Annu. Rev. Biochem. 65: 337.

Greider C.W. and Blackburn E.H. 1985. Identification of a specific telomere terminal transferase activity in Tetrahymena extracts. Cell 43: 405.

1989. A telomeric sequence in the RNA of Tetrahymena telomerase required for telomere repeat synthesis. Nature 337: 331.

Haber J.E. and Thorburn P.C. 1984. Healing of broken linear dicentric chromosomes in yeast. Genetics 106: 207.

Hao L.Y., Strong M., and Greider C.W. 2004. Phosphorylation of H2AX at short telomeres in T cells and fibroblasts. J. Biol. Chem. 279: 45148.

Hao L.Y., Armanios M., Strong M.A., Karim B., Feldser D.M., Huso D., and Greider C.W. 2005. Short telomeres, even in the presence of telomerase, limit tissue renewal capacity. Cell 123: 1121.

Harley C.B., Futcher A.B., and Greider C.W. 1990. Telomeres shorten during ageing of human fibroblasts. Nature 345: 458.

Hathcock K.S., Hemann M.T., Opperman K.K., Strong M.A., Greider C.W., and Hodes R.J. 2002. Haploinsufficiency of mTR results in defects in telomere elongation. Proc. Natl. Acad. Sci. 99: 3591.

Hemann M.T. and Greider C.W. 2000. Wild-derived inbred mouse strains have short telomeres. Nucleic Acids Res. 28: 4474.

Hemann M.T., Hackett J., IJpma A., and Greider C.W. 2000. Telomere length, telomere binding proteins and DNA damage signaling. Cold Spring Harbor Symp. Quant. Biol. 65: 275.

Hemann M.T., Strong M., Hao L.Y., and Greider C.W. 2001a. The shortest telomere, not average telomere length, is critical for cell viability and chromosome stability. Cell 107: 67.

Hemann M.T., Rudolph L., Strong M., DePinho R.A., Chin L., and Greider C.W. 2001b. Telomere dysfunction triggers developmentally regulated germ cell apoptosis. Mol. Biol. Cell 12: 2023.

IJpma A. and Greider C.W. 2003. Short telomeres induce a DNA damage response in Saccharomyces cerevisiae. Mol. Biol. Cell 14: 987.

Lamb J., Harris P.C., Wilkie A.O., Wood W.G., Dauwerse J.G., and Higgs D.R. 1993. De novo truncation of chromosome 16p and healing with (TTAGGG)n in the alpha-thalassemia/mental retardation syndrome (ATR-16). Am. J. Hum. Genet. 52: 668.

Lee H.-W., Blasco M.A., Gottlieb G.J., Horner J.W., Greider C.W., and DePinho R.A. 1998. Essential role of mouse telomerase in highly proliferative organs. Nature 392: 569. 
Lingner J., Hughes T.R., Shevchenko A., Mann M., Lundblad V., and Cech T.R. 1997. Reverse transcriptase motifs in the catalytic subunit of telomerase. Science 276: 561.

Lundblad V. and Szostak J.W. 1989. A mutant with a defect in telomere elongation leads to senescence in yeast. Cell 57: 633 .

Mozdy A.D. and Cech T.R. 2006. Low abundance of telomerase in yeast: Implications for telomerase haploinsufficiency. $R N A$ 12: 1721 .

Naito T., Matsuura A., and Ishikawa F. 1998. Circular chromosome formation in a fission yeast mutant defective in two ATM homologues. Nat. Genet. 20: 203.

Olovnikov A.M. 1973. A theory of marginotomy. J. Theor. Biol. 41: 181.

Qi L., Strong M.A., Karim B.O., Armanios M., Huso D.L., and Greider C.W. 2003. Short telomeres and ataxia-telangiectasia mutated deficiency cooperatively increase telomere dysfunction and suppress tumorigenesis. Cancer Res. 63: 8188 .

Ritchie K.B., Mallory J.C., and Petes T.D. 1999. Interactions of TLC1 (which encodes the RNA subunit of telomerase), TEL1, and MEC1 in regulating telomere length in the yeast Saccharomyces cerevisiae. Mol. Cell. Biol. 19: 6065.

Rudolph K.L., Millard M., Bosenberg M.W., and DePinho R.A. 2001. Telomere dysfunction and evolution of intestinal carcinoma in mice and humans. Nat. Genet. 28: 155.

Shay J.W. and Wright W.E. 2002. Telomerase: A target for cancer therapeutics. Cancer Cell 2: 257.

Shore D. 1997a. Telomerase and telomere-binding proteins: Controlling the endgame. Trends Biochem. Sci. 22: 233. 1997b. Telomere length regulation: Getting the measure of chromosome ends. Biol. Chem. 378: 591.

Singer M.S. and Gottschling D.E. 1994. TLC1: Template RNA component of Saccharomyces cerevisiae telomerase. Science 266: 404

Smogorzewska A. and de Lange T. 2004. Regulation of telomerase by telomeric proteins. Annu. Rev. Biochem. 73: 177.

Viprakasit V., Kidd A.M., Ayyub H., Horsley S., Hughes J., and Higgs D.R. 2003. De novo deletion within the telomeric region flanking the human alpha globin locus as a cause of alpha thalassaemia. Br. J. Haematol. 120: 867.

Vodenicharov M.D. and Wellinger R.J. 2006. DNA degradation at unprotected telomeres in yeast is regulated by the CDK1 (Cdc28/Clb) cell-cycle kinase. Mol. Cell 24: 127.

Vulliamy T., Marrone A., Goldman F., Dearlove A., Bessler M., Mason P.J., and Dokal I. 2001. The RNA component of telomerase is mutated in autosomal dominant dyskeratosis congenita. Nature 413: 432.

Watson J.D. 1972. Origin of concatameric T7 DNA. Nat. New Biol. 239: 197.

Wilkie A.O., Lamb J., Harris P.C., Finney R.D., and Higgs D.R. 1990. A truncated human chromosome 16 associated with alpha thalassaemia is stabilized by addition of telomeric repeat (TTAGGG)n. Nature 346: 868.

Wong K.K., Maser R.S., Bachoo R.M., Menon J., Carrasco D.R., Gu Y., Alt F.W., and DePinho R.A. 2003. Telomere dysfunction and Atm deficiency compromises organ homeostasis and accelerates ageing. Nature 421: 643. 


\section{$8_{\mathrm{CSH}}^{\infty} \mathrm{H}$ Cold Spring Harbor Symposia SYMPOSIA On Quantitative Biology}

\section{Telomerase RNA Levels Limit the Telomere Length Equilibrium}

C.W. GREIDER

Cold Spring Harb Symp Quant Biol 2006 71: 225-229

Access the most recent version at doi:10.1101/sqb.2006.71.063

References This article cites 44 articles, 12 of which can be accessed free at: http://symposium.cshlp.org/content/71/225.full.html\#ref-list-1

License

Email Alerting Receive free email alerts when new articles cite this article - sign up in Service the box at the top right corner of the article or click here. 